\title{
Viruses, Other Pathogenic Microorganisms and Esophageal Cancer
}

\author{
Wenjia Xu Zhongshun Liu Qunchao Bao Zhikang Qian \\ Unit of Herpesvirus and Molecular Virology, Key Laboratory of Molecular Virology \& \\ Immunology, Institut Pasteur of Shanghai, Chinese Academy of Sciences, Shanghai, China
}

\section{Key Words}

Bacterial biota - Epstein-Barr virus · Esophageal cancer - Esophageal squamous cell carcinoma $\cdot$ Human papillomavirus

\begin{abstract}
Background: Esophageal cancer (EC) is the eighth most prevalent malignant tumor and the sixth leading cause of cancer mortality throughout the world. Despite the technical developments in diagnosis and treatment, the 5-year survival rate is still low. The etiology of EC remains poorly understood; multiple risk factors may be involved and account for the great variation in EC incidence in different geographic regions. Summary: Infection with carcinogenetic pathogens has been proposed as a risk factor for EC. This review explores the recent studies on the association of human papillomavirus (HPV), Epstein-Barr virus (EBV), Helicobacter pylori and esophageal bacterial biota with EC. Key Message: Among the above-mentioned pathogens, HPV most likely contributes to esophageal squamous cell carcinoma (ESCC) in high-risk populations. New techniques are being applied to studies on the role of infection in EC, which will inevitably bring novel ideas to the field in the near future. Practical Implications: Multiple meta-analyses support the finding of a higher HPV detection rate in regions associated with high risk for ESCC compared to low-risk areas. A potential role of HPV in the rise of esophageal adenocarcinoma (EAC) was proposed recently. However, further studies are required before a firm conclusion can be drawn. Less work has been done in studying the association between EBV and ESCC, and the results are quite controversial. H. pylori infection is found to be inversely related to $E C$, which is probably due to the reduced incidence of gastroesophageal reflux disease. Analysis of the esophageal bacterial biota revealed distinct clusters of bacteria in normal and diseased esophagi. A type II microbiome rich in Gram-negative bacteria potentially contributes to EAC by inducing chronic inflammation. Novel findings from such studies as these may benefit public health by justifying anti-infection measures to prevent EC.
\end{abstract}




\section{Introduction}

Esophageal cancer (EC) is the eighth most prevalent malignant tumor and the sixth leading cause of cancer mortality throughout the world, with about 500,000 new cases diagnosed each year, and it causes an estimated 406,000 deaths annually [1]. Esophageal squamous cell carcinoma (ESCC) and esophageal adenocarcinoma (EAC) are the two main types of EC. ESCC is the predominant subtype, but the incidence of EAC has been rising in developed countries in recent decades [2]. The 5-year survival rate of patients with early-stage tumors is $>90 \%$ after routine treatment [3]. However, the survival rate dramatically decreases in latestage patients [4]. Owing to the fact that the majority of patients present to hospital at a late stage, the overall 5-year survival rate for EC is only about $20 \%$ [5].

The etiology of EC remains poorly understood; a multifactorial etiology may account for the great variability of EC incidence among different ethnic groups and geographic regions [1, 6]. Epidemiological studies have revealed that tobacco and alcohol consumption are the major risk factors for ESCC [7]. However, additional risk factors include poor oral hygiene, malnutrition and infection. Infections with viruses and bacteria, such as hepatitis B and Helicobacter pylori, have been shown to be strong risk factors for certain types of cancer. About $16 \%$ of cancer cases on average can be attributed to infections, and the frequency is higher in less developed regions than in more developed regions [8]. The role of infection in the development of EC has long been suspected. For example, the first report of an association between human papillomavirus (HPV) infection and ESCC dates back to the early 1980s [9]. However, a firm link between infection and EC development is still missing, despite a large number of studies on this topic. Herein we will review the recent progress in the field, with a focus on the major tumor-causing agents HPV, Epstein-Barr virus (EBV) and H. pylori. The most recent understanding of the role of the esophageal bacterial biota in esophageal disease is also included.

\section{HPV and EC}

\section{HPV Biology}

HPV belongs to the papillomaviridae, a large family of epitheliotropic DNA viruses with over 150 genotypes. They are non-enveloped DNA viruses containing a double-stranded circular DNA genome of $\sim 8 \mathrm{~kb}$. HPV infection was first shown to be correlated with cervical cancer development in the 1980s, and its role in squamous cell carcinomas of the anogenital tract and a fraction of oral carcinomas is well accepted. Nowadays, HPV infection is considered to contribute to approximately $5 \%$ of all human cancers $[10,11]$. Based on the ability of HPVs to transform host cells, the minority of HPV types that infect mucosal tissues and the genital tract are subdivided into high-risk and low-risk categories. The high-risk HPV (hrHPV) types, such as HPV16 and HPV18, have the ability to cause human cancer. In contrast, low-risk HPV types, such as HPV6 and HPV11, cause benign genital warts, but not cancer [12-14].

The HPV genome is organized into three distinct regions, namely the early, late and a long control region [14]. The early region encodes viral non-structural proteins including E1, E2, E4, E5, E6 and E7. The late region encodes L1 and L2 open reading frames that can produce major (L1) and minor (L2) capsid proteins for virion assembly [14]. HPV gene expression and the viral life cycle are tightly controlled by epithelial cell differentiation [15]. It is postulated that scratching of the epithelial tissue allows the virus to infect undifferentiated cells in the basal layers of stratified squamous epithelium. Virus early gene expression is initiated in undifferentiated or intermediately differentiated keratinocytes, but late capsid proteins required for virion assembly are only expressed in keratinocytes undergoing terminal differen- 
tiation near the apical surface of the epithelium [15]. Early proteins E1 and E2 mainly play roles in regulating viral gene transcription and virus replication, while the E5, E6 and E7 of hrHPVs contribute to virus-induced cellular transformation $[14,16]$.

\section{HPV Oncogenesis}

Professor Harald zur Hausen made the first discovery that HPV was related to cancer biology more than 30 years ago, and jointly won the Nobel Prize for the discovery of the HPV cervical cancer virus in $2008[17,18]$. It has been well accepted that HPV causes all uterine cervix cancers. Data from the International Agency for Research on Cancer (IARC) demonstrated that HPV16, 18, 31, 33, 35, 39, 45, 51, 52, 56, 58, 59 and 66 can result in cervical cancer [19]. Among these, HPV16 and HPV18 are regarded as related to $70 \%$ of all cervical cancer cases [19].

Integration of viral DNA into the host genome is one of the factors associated with carcinogenesis. Many cervical carcinomas caused by hrHPV contain integrated viral genome fragments. Integration has the potential to upregulate cellular oncogene expression, which may contribute to oncogenesis [20]. Integration of the HPV genome often disrupts expression of the repressive E2 gene and thus leads to abnormal expression of E6 and E7, which are very potent oncoproteins [21]. HPV-positive cervical cancer cell lines show almost strict reliance on these two oncoproteins (sometimes also including E5) to maintain their transformed phenotype.

The hrHPV E7 protein interacts with tumor suppressor pRB and targets it for proteasome-dependent degradation, which eliminates a cell cycle brake and stimulates differentiated epithelial cells to re-enter the cell cycle for continuous proliferation. p53 is another tumor suppressor that senses abnormal cell cycle progression. Its activation by oncogeneinduced stress functions as a checkpoint to prevent transformation by inducing cellular senescence or apoptosis. In concert with its associated protein E6AP, a cellular ubiquitin ligase, hrHPV E6 targets p53 for degradation. The hrHPV E6 also upregulates telomerase expression, which renders transformed cells able to replicate perpetually [22, 23].

\section{Detection of HPV in EC}

In 1982, Syrjänen $[9,24]$ first suggested the possibility that HPV might play an etiologic role in the progress of both benign and malignant squamous cell carcinoma of the esophagus; an indirect immunoperoxidase-peroxidase-antiperoxidase technique was used. This opened up a new area of HPV research. Many techniques were used to find evidence of the involvement of HPV in ESCC. Filter in situ hybridization (ISH) was commonly used in the late 1980s but was abandoned because of low sensitivity and poor specificity [25]. PCR and real-time quantitative reverse transcription PCR (real-time qRT-PCR) are the most commonly used techniques. They are fast and convenient methods for identifying HPV DNA and its types, and viral load can be analyzed by real-time qRT-PCR [26-30]. Other methods involved in studies of HPV and ESCC include ISH and enzyme-linked immunosorbent assay (ELISA) [27, 31]. However, techniques based on high-throughput analysis are developing rapidly; gene chips and genome-wide association studies are also used in research [32, 33]. Moreover, metaanalysis, a type of data analysis based on the results of previous studies, has been used to investigate the prevalence of HPV in ESCC [34-36].

\section{HPV and ESCC}

There have been a wide range of studies on this topic from various countries, including China, Korea, Iran, India, the United States and Australia. However, in different researches the frequency of HPV infection varies from 0 to $88 \%$ in patients with esophageal pre-malignant lesions or carcinomas [36]. Thus, the association of HPV and ESCC is still controversial. 


\section{Evidence of a Positive Association between HPV and ESCC}

In studies reported from 1992 to 2013, the prevalence of HPV in patients with ESCC was found to be higher in Asia (26.3\%) than in Europe and America (14.0\%). Studies from highrisk regions in China (Anyang, Xinjiang, Sichuan) indicated that there was strong evidence of an association between HPV and ESCC [31, 32, 37]. He et al. [31] tested samples from 1,435 patients with ESCC from Anyang (China); the serological results demonstrated that the presence of HPV16 E7 was associated with an increased risk of ESCC. Chen et al. [32] screened HPV types associated with ESCC of Kazakh from Xinjiang (China) by gene chip; their results showed that the rate of infection with HPV was $66.67 \%$ in the ESCC group, while that of HPV16 was $97.72 \%$ and the rate of co-infection with HPV16 and HPV18 was $2.27 \%$. A hospitalbased case-control study of 99 patients with ESCC and 100 healthy controls in an Australian cohort suggested that HPV may be an additional risk factor in the multifactorial etiology of EC, although a larger, better-powered study is needed [29].

\section{Evidence of a Negative Association between HPV and ESCC}

Some studies have shown no evidence of HPV infection in patients with ESCC. Antunes et al. [28] and Herbster et al. [38] from Brazil as well as Koh et al. [39] from the Korean Cancer Centre Hospital found that tests for HPV DNA were negative in all their samples. Lofdahl et al. [40] set up a population-based study relating HPV infection to tumor site in patients diagnosed with ESCC in Stockholm County in Sweden in 1999-2006. They found that among 204 patients, $10 \%$ had tumors harboring HPV DNA, and tumors containing HPV were not overrepresented in the upper compared with the middle or lower third of the esophagus. The authors concluded that HPV was of uncertain oncogenic relevance in ESCC, and they did not demonstrate that HPV was more strongly associated with proximal than distal tumors. An InterSCOPE collaboration study carried out in 2012 examined samples from six countries/regions for multiple HPV serological markers and analyzed their association with ESCC; they concluded that there was 'limited serological evidence' for an association between HPV infection and ESCC [41].

\section{HPV and EAC}

The incidence of EAC has increased dramatically in developed countries in the past two decades. HPV infection is believed to be responsible for the dramatic rise in head and neck cancers in western countries, which leads to a suspicion that HPV may also play a role in EAC. However, very few investigations of an association between HPV and EAC have been reported, and no evidence of association was found according to these reports [42]. Recently, Rajendra and colleagues [42, 43] reported for the first time that transcriptionally active hrHPV was strongly associated with EAC. They also showed that increasing viral load and active virus transcription were significantly associated with disease severity in the Barrett's metaplasiadysplasia-adenocarcinoma pathway. Their findings justify further research on this issue.

\section{Analysis Based on Previous Studies: Meta-Analysis}

In order to determine the extent of the association between HPV infection and ESCC on a global scale, many reviews published in 2013 and 2014 have summarized previous studies using meta-analyses. In table 1 we show data from six reviews based on meta-analysis. There are multiple methods of detection with different sensitivities for HPV detection. Most research has been based on PCR, and previous studies have shown that PCR and ISH are almost equivalent in HPV detection [44]. Table 1 suggests a lower prevalence in studies using ISH than in those using PCR. However, use of immunohistochemistry (IHC) and serology led to a higher prevalence of HPV in ESCC than was found by PCR. All six reviews summarized the prevalence of HPV in ESCC, and four of them also calculated the odds ratio (OR) by analysis of casecontrol studies $[35,36,45,46]$. For the meta-analyses, the lowest number of studies selected 
Gastro

Intestinal

Tumors

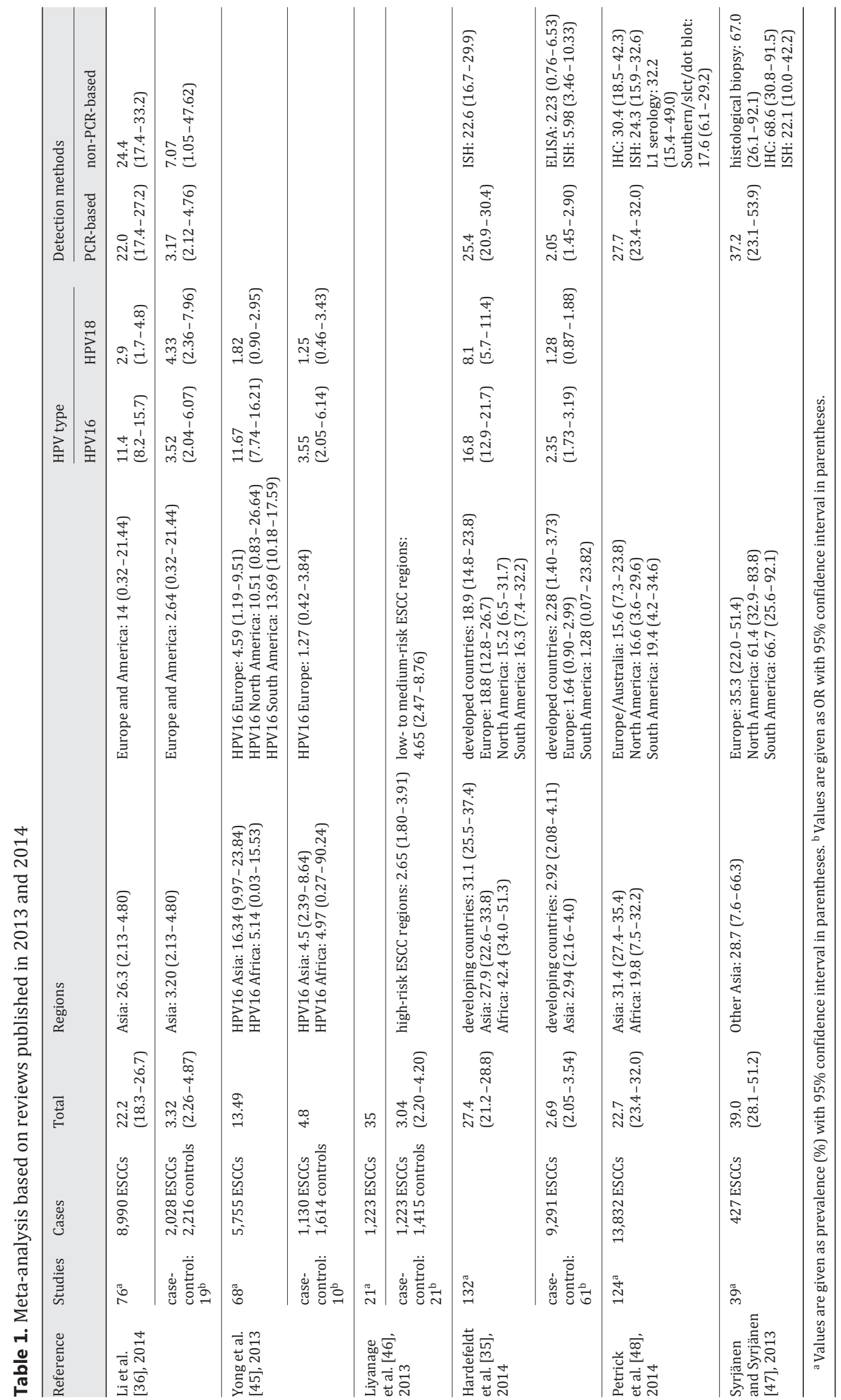

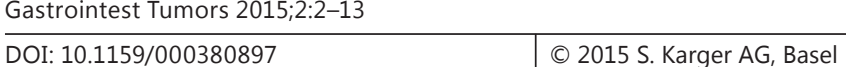

www.karger.com/gat

Xu et al.: Viruses, Other Pathogenic Microorganisms and Esophageal Cancer 
was 21 [46] and the number of ESCC cases was at least 427 [47]; the highest number of studies selected was 132 [35] and the number of ESCC cases included was 13,832 [48]. In table 1, the prevalence of HPV in ESCC given by each meta-analysis is seen to range from 13.49 to 39\%, which is lower than that of cervical squamous cell carcinoma (86.9\%) [36]. The summary OR varied from 2.69 to 4.80 (mean 3.46); these ORs suggest an approximate threefold increased risk of ESCC in the presence of HPV.

Table 1 also depicts the subgroup analyses of HPV in patients with ESCC, indicating variation with geographic area, HPV type and detection method. The prevalence in developing countries is $12.2 \%$ higher than in developed countries, and the OR indicates a greater risk in developing countries, which is in accordance with prevalence data [35]. Africa has the highest prevalence, at $42.4 \%$, among all regions in the study of Hardefeldt et al. [35]; however, the prevalence was $19.8 \%$ and a surprising $5.14 \%$ in other two reviews $[45,48]$. In a metaanalysis from Asia, in which the largest population was Chinese (in more than half of the studies included), the prevalence ranged from 16.34 to $31.4 \%[35,36,45,48]$. From the point estimate of risk, Asia (ORs 3.2-4.5) has a significantly higher risk of HPV in patients with ESCC than Europe or America (ORs 1.27-2.64) [35, 36, 45].

Given that HPV16 and HPV18 are the most frequently detected types in HPV-associated cancers, table 1 only displays HPV16/18 subtypes. Yong et al. [45] evaluated the prevalence of HPV16 and HPV18 in ESCC and found 11.67\% (HPV16) and 1.82\% (HPV18). They also calculated separate ORs for HPV16 (OR 3.55) and HPV18 (OR 1.25) and found that HPV16 was the most frequently observed subtype in ESCC. The prevalence values calculated in two other reviews are in accordance with the report by Yong et al. [35, 36]. Overall, meta-analyses in the reviews involving subgroups with different HPV types indicated that HPV16 is significantly associated with the risk of ESCC.

\section{Association between EBV Infection and ESCC}

EBV is a member of the gamma-herpesvirus family which was discovered more than 40 years ago. EBV is a widespread pathogen that is found in all human populations and establishes lifelong asymptomatic latent infection [49]. EBV preferentially infects B lymphocytes and infection of other cell types (e.g. epithelial cells) is less efficient. EBV is able to transform resting B cells into lymphoblastoid cell lines, whereas infection of epithelial cells in vitro does not involve this process. During latent infection, a limited viral genome is expressed, incorporating six EBV nuclear proteins (EBNAs 1, 2, 3A, 3B, 3C and LP) and three latent membrane proteins (LMPs 1, 2A and 2B) [49].

$\mathrm{EBV}$ is an oncogenic virus that has been reported to be associated with Burkitt's lymphoma, Hodgkin's disease, breast cancer, nasopharyngeal carcinoma, gastric carcinoma and leiomyosarcoma [50]. However, whether EBV is related to ESCC remains controversial: there are limited studies and their conclusions disagree. Different assays with varying sensitivity and specificity have been used to investigate specimens from different regions or countries. Mizobuchi et al. [51] from Japan examined 41 surgical specimens as well as 12 cell lines of ESCC by amplifying the EBV EBNA-1 gene using PCR and found no EBV genome in cases of EC. Yanai et al. [52], also from Japan, found no EBER-1-positive cancer cells in any EC lesion tested by real-time quantitative PCR. Sunpaweravong et al. [53], from Thailand, found no EBER-positive cancer cells by ISH, but reported five samples in which EBER-positive tumor-infiltrating lymphocytes were found. Wang et al. [54], from northern China, evaluated 51 differentiated tumors by ISH using an antisense probe against EBV-encoded small RNA-1 and PCR amplification for the EBV BamHI W fragment; they found that EBV was negative by both ISH and PCR. In contrast, another study from Taiwan detected EBV DNA by PCR in 11 samples (35.5\%) from 31 patients with ESCC. 
Expression of EBERs in ESCC was further confirmed with ISH, whereas no LMP-1 expression was detected, indicating that EBV may be associated with ESCC [55]. Jenkins et al. [56] from the USA found EBV in 8.3\% (5/60) of cases by PCR. In Germany, Awerkiew et al. [57] confirmed the association. EBV DNA was detected in $35 \%$ of squamous cell carcinomas and $36 \%$ of adenocarcinomas by nested PCR, which is more sensitive than conventional PCR. The most convincing report is from Shantou, located in South China. EBV EBER and LMP-1 proteins were identified in 10 (6.1\%) EC specimens by both ISH and IHC. The 10 EBV-associated carcinomas were all poorly differentiated squamous cell carcinomas or undifferentiated carcinomas accompanied by heavy degrees of lymphocyte infiltration in the tumor stroma. This suggests an association between EBV infection, EC cell differentiation and lymphocyte infiltration [58].

Owing to different detection techniques and geographic factors, the results of such studies are variable even in one country (China). ISH (using an EBER probe) and IHC (using antibodies against LMP-1, etc.) are better than PCR (amplifying the EBNA-1 gene) for investigating the presence of EBV in ESCC because of cross-contamination with tumor-infiltrating lymphocytes surrounding the carcinoma. Considering the contradictory results obtained using ISH, racial and geographic factors seem to play a role in the number of cases detected by different laboratories. Also, ISH may produce false-negative results due to a higher rate of RNA degradation. It would be favorable for the prevention and diagnosis of poorly differentiated or undifferentiated ESCC if the association between EBV infection and lymphocyte infiltration were to be validated.

In summary, despite some negative reports, EBV infection has a relationship with at least some subtypes of ESCC, to some extent, in certain races and countries. More and larger studies are required from other parts of the world, using standardized detection methods, to further elucidate the association between EBV and ESCC.

\section{Helicobacter pylori and Esophageal Carcinoma}

H. pylori is the most frequently observed bacterium in reports of gastric carcinoma. As H. pylori can induce superficial gastritis, a series of animal and clinical studies have demonstrated that it contributes to the development of gastric carcinoma [59]. More than half of the world's human population has been infected by $H$. pylori, and the proportion infected in developing countries is larger than that in developed countries [60]. In recent years, however, carriage of $H$. pylori has been controlled by the application of antibiotics [61]. This has led to a significant decline in gastric cancer and a dramatic increase in EC [62]. Some investigators believe that the reduction of EC associated with $H$. pylori infection is related to the inhibition of acid production caused by $H$. pylori by its stimulation of atrophic gastritis [63]. The cag+ strains of $H$. pylori are associated with gastric cancer, and they also induce the production of interleukin 8 (IL-8) [64]. This leads to higher levels of IL-1 $\beta$ and tumor necrosis factor- $\alpha$ (TNF- $\alpha$ ) [65]; these two cytokines reduce acid production and therefore decrease the risk of gastroesophageal reflux. Indeed, H. pylori infection with atrophy of the gastric corpus can lead to a lower incidence of gastroesophageal reflux disease than reported in patients with increased or even normal levels of acid [66].

\section{Esophageal Biota and Esophageal Disease}

Mutualism between the human host and bacterial biota is essential for human health. In luminal organs of the digestive system, a balanced bacterial population may develop the mucosal immune system, maintain the inner environment of these luminal organs or provide 
Table 2. Bacterial biota in the esophagus

\begin{tabular}{llccccc}
\hline Patient group & Firmicutes & Proteobacteria & Fusobacteria & Bacteroides & Actinobacteria & TM7 \\
\hline Normal & $40 \%$ & $49 \%$ & - & $8 \%$ & $3 \%$ & - \\
Reflux esophagitis & $33 \%$ & $43 \%$ & $10 \%$ & $10 \%$ & $2 \%$ & $2 \%$ \\
Barrett's esophagus & $55 \%$ & $20 \%$ & $9 \%$ & $14 \%$ & $2 \%$ & - \\
\hline
\end{tabular}

specific nutrients [67]. Imbalances in the bacterial biota induce a series of health problems, such as H. pylori-induced gastric carcinoma [59]. Therefore, the balance of bacterial biota in the esophagus is important in maintaining the normal physiological environment. Alterations in the bacterial biota may cause esophageal disease and even esophageal tumors.

Traditional culture methods were inappropriate for study of the bacterial biota of the esophagus. The appearance of metagenomics techniques in recent years has increased understanding of the microbial systems in the esophagus [68]. Unlike traditional culture methods, metagenomics does not rely on microbial clonal cultures; DNA samples are obtained directly from the environment being studied. Specific genes, such as the 16S rRNA gene, are sequenced to construct a library or compared with known libraries [69]. After a series of organized analyses, a great deal of information about the genetic material can be obtained and the database can be used as a reference for future work.

Metagenomics has been used to investigate the composition of the bacterial flora of the esophagus. In a study performed in 2004, broad-range 16S rRNA PCR was used to analyze esophageal biopsies from four human adults with normal esophageal mucosa [70]. The data showed that the bacterial biota contained six phyla. Firmicutes, accounting for 626 of 900 clones $(69.6 \%)$ was the most common phylum, the others were Bacteroides (20.2\%), Actinobacteria (4.3\%), Proteobacteria (2.2\%), Fusobacteria (2.2\%) and TM7 (1.4\%). Streptococcus, which is a member of the Firmicutes, accounting for $39 \%$, was the most common genus. In 2013, a similar study was carried out in 18 patients with a normal or diseased esophagus [71]. The results (table 2) showed differences in the bacterial biota among individuals with a normal esophagus, reflux esophagitis and Barrett's esophagus. Both reflux esophagitis and Barrett's esophagus are closely associated with EC.

In 2009, an analysis of the microbial 16S rRNA genes in esophageal biopsies from 34 patients with normal or diseased esophagus classified the microbiome of the esophagus into two types [72]. The type I microbiome mainly comprises Streptococcus and is related to the normal esophagus. The type II microbiome includes many Gram-negative microaerophiles or anaerobes and has a closer relationship with esophageal disease. The type II microbiome may affect the health of the esophagus through two mechanisms that differ from type I. One of those mechanisms is associated with a higher incidence of gastroesophageal reflux disease. The other mechanism is related to the lipopolysaccharide in the cell walls of Gram-negative bacteria. Lipopolysaccharide can induce the nitric oxide synthase pathway, which relaxes the lower esophageal sphincter [73]. This contributes to gastroesophageal reflux, which is associated with a higher incidence of EAC.

\section{Bacterial Infection and Signal Transduction}

As previously stated, the bacterial population may aid development of the mucosal immune system, but it may also induce disease. These processes involve the participation of many signaling pathways.

Cellular receptors and signal factors play important roles in the interaction of bacterial infections and signal transduction in epithelial cells. In luminal organs of the digestive system, 
bacterial populations may change the levels of expression of signal factors or cellular receptors to influence the health of these organs [74]. For example, some bacterial strains, such as $H$. pylori, increase the expression of IL-1 $\beta$, and cells expressing the IL-1 $\beta$ receptor gene may be induced to express inflammatory cytokines [75].

Many epithelial cells produce a type of glycoprotein, called mucin, to protect their surfaces [76]. Some mucins may act as cellular receptors to bind signal factors, such as IL-1, IL-4, IL-6 and TNF- $\alpha$, and therefore influence the inflammatory response. Most are secreted as signal factors to control IgA levels in order to regulate the inflammatory response. Mucins may be affected by bacteria; in particular, MUC2 and MUC5AC can be unregulated by both Gramnegative and Gram-positive bacteria [77]. In addition to their involvement in inflammation, mucins may also contribute directly to tumorigenesis [43]. In one study, MUC2 knockout reduced the size of bowel carcinomas in mice [78]. Mucins can interact with antiapoptotic proteins, such as the trefoil family of peptides, and with the epidermal growth factor receptor family, for example the human epidermal growth factor receptor 2 [79]. This leads to their influence on cell growth and tumorigenesis [76].

In the normal esophagus, mucins are not expressed in squamous mucosal cells. However, in a study in 2006, antibodies against each member of the mucin family were used to stain mucosal biopsies from 35 patients with Barrett's esophagus. It was found that all samples were stained by MUC2, MUC3 and MUC5AC antibodies, and 40 and $90 \%$ of samples from patients with non-dysplastic Barrett's esophagus were stained by MUC1 and MUC6 [80]. Therefore, mucins may play important roles in tumorigenesis in the esophagus.

\section{Conclusions}

EC is one of the most serious malignancies of the gastrointestinal tract. The incidence rate of EC varies dramatically among different ethnic groups and geographic regions. Many risk factors, including smoking, alcohol consumption, poverty and infection, may be involved in EC development. Although a clear-cut association between infection and EC is still missing, there is evidence that HPV infection may contribute to ESCC in certain high-risk populations. Well-controlled studies in large cohorts with more advanced techniques are required. In addition, new techniques are emerging that allow systematic study of the esophageal microbiota and their role in disease. A distinct cluster, the type II microbiome that may contribute to EAC, has been reported. Novel findings from more advanced studies may benefit public health by justifying anti-infection measures, such as HPV vaccination, to prevent EC.

\section{Acknowledgements}

This work was supported by the National Natural Science Foundation of China (grant 81371826 to Z. Qian).

\section{References}

1 Ferlay J, Shin HR, Bray F, Forman D, Mathers C, Parkin DM: Estimates of worldwide burden of cancer in 2008: GLOBOCAN 2008. Int J Cancer 2010;127:2893-2917.

2 Edgren G, Adami HO, Weiderpass E, Nyren O: A global assessment of the oesophageal adenocarcinoma epidemic. Gut 2013;62:1406-1414.

3 Shimizu Y, Tsukagoshi H, Fujita M, Hosokawa M, Kato M, Asaka M: Long-term outcome after endoscopic mucosal resection in patients with esophageal squamous cell carcinoma invading the muscularis mucosae or deeper. Gastrointest Endosc 2002;56:387-390. 
4 Rice TW, Rusch VW, Apperson-Hansen C, Allen MS, Chen LQ, Hunter JG, Kesler KA, Law S, Lerut TE, Reed CE, Salo JA, Scott WJ, Swisher SG, Watson TJ, Blackstone EH: Worldwide esophageal cancer collaboration. Dis Esophagus 2009;22:1-8.

5 Siegel R, Naishadham D, Jemal A: Cancer statistics for Hispanics/Latinos, 2012. CA Cancer J Clin 2012;62: 283-298.

6 Corley DA, Buffler PA: Oesophageal and gastric cardia adenocarcinomas: analysis of regional variation using the Cancer Incidence in Five Continents database. Int J Epidemiol 2001;30:1415-1425.

7 Castellsague X, Munoz N, De Stefani E, Victora CG, Castelletto R, Rolon PA, Quintana MJ: Independent and joint effects of tobacco smoking and alcohol drinking on the risk of esophageal cancer in men and women. Int J Cancer 1999;82:657-664.

8 de Martel C, Ferlay J, Franceschi S, Vignat J, Bray F, Forman D, Plummer M: Global burden of cancers attributable to infections in 2008: a review and synthetic analysis. Lancet Oncol 2012;13:607-615.

9 Syrjanen K, Pyrhonen S, Aukee S, Koskela E: Squamous cell papilloma of the esophagus: a tumour probably caused by human papilloma virus (HPV). Diagn Histopathol 1982;5:291-296.

10 zur Hausen H: Papillomaviruses in the causation of human cancers - a brief historical account. Virology 2009; 384:260-265.

11 Mesri EA, Feitelson MA, Munger K: Human viral oncogenesis: a cancer hallmarks analysis. Cell Host Microbe 2014;15:266-282.

12 de Villiers EM, Fauquet C, Broker TR, Bernard HU, zur Hausen H: Classification of papillomaviruses. Virology 2004;324:17-27.

13 Van Doorslaer K, Tan Q, Xirasagar S, Bandaru S, Gopalan V, Mohamoud Y, Huyen Y, McBride AA: The Papillomavirus Episteme: a central resource for papillomavirus sequence data and analysis. Nucleic Acids Res 2013; 41(database issue):D571-D578.

14 Zheng ZM, Baker CC: Papillomavirus genome structure, expression, and post-transcriptional regulation. Front Biosci 2006;11:2286-2302.

15 Conway MJ, Meyers C: Replication and assembly of human papillomaviruses. J Dent Res 2009;88:307-317.

16 Chiang CM, Ustav M, Stenlund A, Ho TF, Broker TR, Chow LT: Viral E1 and E2 proteins support replication of homologous and heterologous papillomaviral origins. Proc Natl Acad Sci USA 1992;89:5799-5803.

17 de Villiers EM, Gissmann L, zur Hausen H: Molecular cloning of viral DNA from human genital warts. J Virol 1981;40:932-935.

18 Gissmann L, zur Hausen H: Partial characterization of viral DNA from human genital warts (condylomata acuminata). Int J Cancer 1980;25:605-609.

19 Castillo A, Koriyama C, Higashi M, Anwar M, Bukhari MH, Carrascal E, Mancilla L, Okumura H, Matsumoto M, Sugihara K, Natsugoe S, Eizuru Y, Akiba S: Human papillomavirus in upper digestive tract tumors from three countries. World J Gastroenterol 2011;17:5295-5304.

20 Durst M, Croce CM, Gissmann L, Schwarz E, Huebner K: Papillomavirus sequences integrate near cellular oncogenes in some cervical carcinomas. Proc Natl Acad Sci USA 1987;84:1070-1074.

21 Pett MR, Alazawi WO, Roberts I, Dowen S, Smith DI, Stanley MA, Coleman N: Acquisition of high-level chromosomal instability is associated with integration of human papillomavirus type 16 in cervical keratinocytes. Cancer Res 2004;64:1359-1368.

22 McLaughlin-Drubin ME, Meyers J, Munger K: Cancer associated human papillomaviruses. Curr Opin Virol 2012;2:459-466.

23 Moody CA, Laimins LA: Human papillomavirus oncoproteins: pathways to transformation. Nat Rev Cancer 2010;10:550-560.

24 Syrjanen KJ: Histological changes identical to those of condylomatous lesions found in esophageal squamous cell carcinomas. Arch Geschwulstforsch 1982;52:283-292.

25 Syrjanen KJ: HPV infections and oesophageal cancer. J Clin Pathol 2002;55:721-728.

26 Liu F, Guo F, Zhou Y, He Z, Tian X, Guo C, Ning T, Pan Y, Cai H, Ke Y: The Anyang Esophageal Cancer Cohort Study: study design, implementation of fieldwork, and use of computer-aided survey system. PLoS One 2012; 7:e31602.

27 Xu CL, Qian XL, Zhou XS, Zhao QZ, Li YC: Expression of HPV16-E6 and E7 oncoproteins in squamous cell carcinoma tissues of esophageal cancer and non-cancer tissues (in Chinese). Ai Zheng 2004;23:165-168.

28 Antunes LC, Prolla JC, de Barros Lopes A, da Rocha MP, Fagundes RB: No evidence of HPV DNA in esophageal squamous cell carcinoma in a population of Southern Brazil. World J Gastroenterol 2013;19:6598-6603.

29 Liyanage SS, Segelov E, Malik A, Garland SM, Tabrizi SN, Cummins E, Seale H, Rahman B, Moa A, Barbour AP, Crowe PJ, MacIntyre CR: A case-control study of the role of human papillomavirus in oesophageal squamous cell carcinoma in Australia. J Oncol 2014;2014:236482.

30 Wang X, Tian X, Liu F, Zhao Y, Sun M, Chen D, Lu C, Wang Z, Shi X, Zhang Q, Zhang D, Shen Z, Li F, Harris CC, Cai H, Ke Y: Detection of HPV DNA in esophageal cancer specimens from different regions and ethnic groups: a descriptive study. BMC Cancer 2010;10:19.

31 He Z, Xu Z, Hang D, Guo F, Abliz A, Weiss NS, Xi L, Liu F, Ning T, Pan Y, Guo C, Liang Y, Lu C, Zhang L, Cai H, Ke Y: Anti-HPV-E7 seropositivity and risk of esophageal squamous cell carcinoma in a high-risk population in China. Carcinogenesis 2014;35:816-821.

32 Chen WG, Yang CM, Xu LH, Zhang N, Liu XY, Ma YG, Huo XL, Han YS, Tian DA, Zheng Y: Gene chip technology used in the detection of HPV infection in esophageal cancer of Kazakh Chinese in Xinjiang Province.J Huazhong Univ Sci Technolog Med Sci 2014;34:343-347. 
33 Yang J, Wu H, Wei S, Xiong H, Fu X, Qi Z, Jiang Q, Li W, Hu G, Yuan X, Liao Z: HPV seropositivity joints with susceptibility loci identified in Glassy at apoptosis associated genes to increase the risk of esophageal squamous cell carcinoma (ESCC). BMC Cancer 2014;14:501.

34 Gao H, Wang L, Cui S, Wang M: Combination of meta-analysis and graph clustering to identify prognostic markers of ESCC. Genet Mol Biol 2012;35:530-537.

35 Hardefeldt HA, Cox MR, Eslick GD: Association between human papillomavirus (HPV) and oesophageal squamous cell carcinoma: a meta-analysis. Epidemiol Infect 2014;142:1119-1137.

36 Li X, Gao C, Yang Y, Zhou F, Li M, Jin Q, Gao L: Systematic review with meta-analysis: the association between human papillomavirus infection and oesophageal cancer. Aliment Pharmacol Ther 2014;39:270-281.

37 Cao F, Han H, Zhang F, Wang B, Ma W, Wang Y, Sun G, Shi M, Ren Y, Cheng Y: HPV infection in esophageal squamous cell carcinoma and its relationship to the prognosis of patients in northern China. ScientificWorldJournal 2014;2014:804738.

38 Herbster S, Ferraro CT, Koff NK, Rossini A, Kruel CD, Andreollo NA, Rapozo DC, Blanco TC, Faria PA, Santos PT, Albano RM, Simao Tde A, Pinto LF: HPV infection in Brazilian patients with esophageal squamous cell carcinoma: interpopulational differences, lack of correlation with surrogate markers and clinicopathological parameters. Cancer Lett 2012;326:52-58.

39 Koh JS, Lee SS, Baek HJ, Kim YI: No association of high-risk human papillomavirus with esophageal squamous cell carcinomas among Koreans, as determined by polymerase chain reaction. Dis Esophagus 2008;21:114117.

40 Lofdahl HE, Du J, Nasman A, Andersson E, Rubio CA, Lu Y, Ramqvist T, Dalianis T, Lagergren J, Dahlstrand H: Prevalence of human papillomavirus (HPV) in oesophageal squamous cell carcinoma in relation to anatomical site of the tumour. PLoS One 2012;7:e46538.

41 Sitas F, Egger S, Urban MI, Taylor PR, Abnet CC, Boffetta P, O'Connell DL, Whiteman DC, Brennan P, Malekzadeh R, Pawlita M, Dawsey SM, Waterboer T; InterSCOPE Collaboration: InterSCOPE study: associations between esophageal squamous cell carcinoma and human papillomavirus serological markers. J Natl Cancer Inst 2012; 104:147-158.

42 Rajendra S, Wang B, Snow ET, Sharma P, Pavey D, Merrett N, Ball MJ, Brain T, Fernando R, Robertson IK: Transcriptionally active human papillomavirus is strongly associated with Barrett's dysplasia and esophageal adenocarcinoma. Am J Gastroenterol 2013;108:1082-1093.

43 Al-Haddad S, El-Zimaity H, Hafezi-Bakhtiari S, Rajendra S, Streutker CJ, Vajpeyi R, Wang B: Infection and esophageal cancer. Ann NY Acad Sci 2014;1325:187-196.

44 Wiedorn KH, Kuhl H, Galle J, Caselitz J, Vollmer E: Comparison of in-situ hybridization, direct and indirect in-situ PCR as well as tyramide signal amplification for the detection of HPV. Histochem Cell Biol 1999;111: 89-95.

45 Yong F, Xudong N, Lijie T: Human papillomavirus types 16 and 18 in esophagus squamous cell carcinoma: a meta-analysis. Ann Epidemiol 2013;23:726-734.

46 Liyanage SS, Rahman B, Ridda I, Newall AT, Tabrizi SN, Garland SM, Segelov E, Seale H, Crowe PJ, Moa A, MacIntyre CR: The aetiological role of human papillomavirus in oesophageal squamous cell carcinoma: a meta-analysis. PLoS One 2013;8:e69238.

47 Syrjanen K, Syrjanen S: Detection of human papillomavirus in sinonasal carcinoma: systematic review and meta-analysis. Hum Pathol 2013;44:983-991.

48 Petrick JL, Wyss AB, Butler AM, Cummings C, Sun X, Poole C, Smith JS, Olshan AF: Prevalence of human papillomavirus among oesophageal squamous cell carcinoma cases: systematic review and meta-analysis. $\mathrm{Br} \mathrm{J}$ Cancer 2014;110:2369-2377.

49 Young LS, Rickinson AB: Epstein-Barr virus: 40 years on. Nat Rev Cancer 2004;4:757-768.

50 Thompson MP, Kurzrock R: Epstein-Barr virus and cancer. Clin Cancer Res 2004;10:803-821.

51 Mizobuchi S, Sakamoto H, Tachimori Y, Kato H, Watanabe H, Terada M: Absence of human papillomavirus-16 and -18 DNA and Epstein-Barr virus DNA in esophageal squamous cell carcinoma. Jpn J Clin Oncol 1997;27: $1-5$.

52 Yanai H, Hirano A, Matsusaki K, Kawano T, Miura O, Yoshida T, Okita K, Shimizu N: Epstein-Barr virus association is rare in esophageal squamous cell carcinoma. Int J Gastrointest Cancer 2003;33:165-170.

53 Sunpaweravong S, Mitarnun W, Puttawibul P: Absence of Epstein-Barr virus in esophageal squamous cell carcinoma. Dis Esophagus 2005;18:398-399.

54 Wang J, Noffsinger A, Stemmermann G, Fenoglio-Preiser C: Esophageal squamous cell carcinomas arising in patients from a high-risk area of North China lack an association with Epstein-Barr virus. Cancer Epidemiol Biomarkers Prev 1999;8:1111-1114.

55 Wang LS, Chow KC, Wu YC, Li WY, Huang MH: Detection of Epstein-Barr virus in esophageal squamous cell carcinoma in Taiwan. Am J Gastroenterol 1999;94:2834-2839.

56 Jenkins TD, Nakagawa H, Rustgi AK: The association of Epstein-Barr virus DNA with esophageal squamous cell carcinoma. Oncogene 1996;13:1809-1813.

57 Awerkiew S, Bollschweiler E, Metzger R, Schneider PM, Holscher AH, Pfister H: Esophageal cancer in Germany is associated with Epstein-Barr-virus but not with papillomaviruses. Med Microbiol Immunol 2003;192:137140.

58 Wu MY, Wu XY, Zhuang CX: Detection of HSV and EBV in esophageal carcinomas from a high-incidence area in Shantou China. Dis Esophagus 2005;18:46-50. 
59 Peek RM Jr, Blaser MJ: Helicobacter pylori and gastrointestinal tract adenocarcinomas. Nat Rev Cancer 2002; 2:28-37.

60 de Korwin JD: Epidemiology of Helicobacter pylori infection and gastric cancer (in French). Rev Prat 2014;64: 189-193.

61 Cheng HC, Wang JD, Chen WY, Chen CW, Chang SC, Sheu BS: Helicobacter pylori test-and-treat program can be cost-effective to prevent gastric cancer in Taiwanese adults: referred to the nationwide reimbursement database. Helicobacter 2015;20:114-124.

62 Devesa SS, Blot WJ, Fraumeni JF Jr: Changing patterns in the incidence of esophageal and gastric carcinoma in the United States. Cancer 1998;83:2049-2053.

63 Koike T, Ohara S, Sekine H, Iijima K, Kato K, Shimosegawa T, Toyota T: Helicobacter pylori infection inhibits reflux esophagitis by inducing atrophic gastritis. Am J Gastroenterol 1999;94:3468-3472.

64 Tummuru MKR, Sharma SA, Blaser MJ: Helicobacter pylori picB, a homologue of the Bordetella pertussis toxin secretion protein, is required for induction of IL-8 in gastric epithelial cells. Mol Microbiol 1995;18:867-876.

65 Glocker E, Lange C, Covacci A, Bereswill S, Kist M, Pahl HL: Proteins encoded by the cag pathogenicity island of Helicobacter pylori are required for NF-kappaB activation. Infect Immun 1998;66:2346-2348.

66 Hatakeyama M, Brzozowski T: Pathogenesis of Helicobacter pylori infection. Helicobacter 2006;11(suppl 1): $14-20$.

67 Cunningham-Rundles S, Ahrn S, Abuav-Nussbaum R, Dnistrian A: Development of immunocompetence: role of micronutrients and microorganisms. Nutr Rev 2002;60(5 Pt 2):S68-S72.

68 Wang ZK, Yang YS: Upper gastrointestinal microbiota and digestive diseases. World J Gastroenterol 2013;19: 1541-1550.

69 Hugenholtz P, Goebel BM, Pace NR: Impact of culture-independent studies on the emerging phylogenetic view of bacterial diversity. J Bacteriol 1998;180:4765-4774.

70 Pei Z, Bini EJ, Yang L, Zhou M, Francois F, Blaser MJ: Bacterial biota in the human distal esophagus. Proc Natl Acad Sci USA 2004;101:4250-4255.

71 Liu N, Ando T, Ishiguro K, Maeda O, Watanabe O, Funasaka K, Nakamura M, Miyahara R, Ohmiya N, Goto H: Characterization of bacterial biota in the distal esophagus of Japanese patients with reflux esophagitis and Barrett's esophagus. BMC Infect Dis 2013;13:130.

72 Yang L, Lu X, Nossa CW, Francois F, Peek RM, Pei Z: Inflammation and intestinal metaplasia of the distal esophagus are associated with alterations in the microbiome. Gastroenterology 2009;137:588-597.

73 Fan YP, Chakder S, Gao F, Rattan S: Inducible and neuronal nitric oxide synthase involvement in lipopolysaccharide-induced sphincteric dysfunction. Am J Physiol Gastrointest Liver Physiol 2001;280:G32-G42.

74 Houghton J, Korah RM, Condon MR, Kim KH: Apoptosis in Helicobacter pylori associated gastric and duodenal ulcer disease is mediated via the Fas antigen pathway. Dig Dis Sci 1999;44:465-478.

75 El-Omar EM, Carrington M, Chow WH, McColl KEL, Bream JH, Young HA, Herrera J, Lissowska J, Yuan CC, Rothman N, Lanyon G, Martin M, Fraumeni JF, Rabkin CS: Interleukin-1 polymorphisms associated with increased risk of gastric cancer. Nature 2000;404:398-402.

76 Hollingsworth MA, Swanson BJ: Mucins in cancer: protection and control of the cell surface. Nat Rev Cancer 2004;4:45-60.

77 Dohrman A, Miyata S, Gallup M, Li JD, Chapelin C, Coste A, Escudier E, Nadel J, Basbaum C: Mucin gene (MUC 2 and MUC 5AC) upregulation by Gram-positive and Gram-negative bacteria. Biochim Biophys Acta 1998;1406: 251-259.

78 Velcich A, Yang W, Heyer J, Fragale A, Nicholas C, Viani S, Kucherlapati R, Lipkin M, Yang K, Augenlicht L: Colorectal cancer in mice genetically deficient in the mucin Muc2. Science 2002;295:1726-1729.

79 Komatsu M, Jepson S, Arango ME, Carothers Carraway CA, Carraway KL: Muc4/sialomucin complex, an intramembrane modulator of ErbB2/HER2/Neu, potentiates primary tumor growth and suppresses apoptosis in a xenotransplanted tumor. Oncogene 2001;20:461-470.

80 Glickman JN, Blount PL, Sanchez CA, Cowan DS, Wongsurawat VJ, Reid B, Odze RD: Mucin core polypeptide expression in the progression of neoplasia in Barrett's esophagus. Hum Pathol 2006;37:1304-1315. 